\title{
Access to Stereotactic Radiosurgery: Identification of Existing Disparities and a Modest Proposal to Reduce Them
}

Francis Fezeu ${ }^{1}$, Ahmed J. Awad ${ }^{2}$, Colin J. Przybylowski ${ }^{3}$, Robert M. Starke ${ }^{4}$, Yuval Grober ${ }^{4}$, David Schlesinger ${ }^{5}$, Cheng-chia Lee ${ }^{6}$, Zhiyuan $\mathrm{Xu}^{4}$, Jason Sheehan ${ }^{7}$

1. Department of Neurosurgery, University of Virginia Health System, Charlottesville, Virginia 2. Faculty of Medicine and Health Sciences, An-Najah National University, Nablus, Palestine 3. Department of Neurosurgery, University of Virginia Health System, Charlottesville, VA 4. Department of Neurological Surgery, University of Virginia Health System, Charlottesville, Virginia 5. Department of Radiation Oncology, University of Virginia Health System, Charlottesville, Virginia 6. Department of Neurosurgery, Taipei Veterans Genenral Hospital 7. University of Virginia School of Medicine

$\square$ Corresponding author: Francis Fezeu, francisfezeu@yahoo.com

Disclosures can be found in Additional Information at the end of the article

\section{Abstract}

\section{Introduction}

Despite the abundance of literature demonstrating the safety, efficacy, and cost-effectiveness of radiosurgery, access to radiosurgery in some parts of the world remains limited. The purpose of this report is to identify disparities for stereotactic radiosurgery (SRS) and suggest possible solutions.

\section{Methods}

In this study, we only focus on one SRS device (Gamma Knife) for SRS availability and cost data. We utilized information from Elekta $A B$ to identify Gamma Knife device sales and the records of the World Bank in order to calculate the ratio of Gamma Knife devices per capita. According to evidence-based data of medical oncology in the United States of America (USA), we assumed that $18 \%$ of gross domestic product (GDP) goes to healthcare spending, approximately $5 \%$ of healthcare spending goes to cancer care, and up to $30 \%$ of cancer care could be spent on radiosurgery.

\section{Results}

As of 2013, one Gamma Knife unit is available for approximately three million people in USA, Canada, Japan, and the Republic of Korea. In contrast, there is one Gamma Knife unit for 370 million people in Africa, 90 million people in China, 47 million people in Central and Latin

Received 12/03/2013 Review began 12/04/2013 Published 01/20/2014

\section{(๑) Copyright 2014}

Fezeu et al. This is an open access article distributed under the terms of the Creative Commons Attribution License CC-BY 3.0., which permits unrestricted use, distribution, and reproduction in any medium, provided the original author and source are credited. America, 43 million people in Asia (excluding China, Japan, and the Republic of Korea), 36 million people in Australia, and 15 million people in Europe.

According to their respective GDPs, these regions can afford to purchase the following numbers of Gamma Knife devices, respectively (assuming a unit cost of \$4 million): European Union 11,225, USA - 9,400, East Asia and Pacific region - 7,054, Latin America and Caribbean - 3,600, Middle East and North Africa - 1,039, and sub-Saharan Africa - 869.

Regional medical policies in West Africa, South Africa, and East Africa could have a significant beneficial effect by making radiosurgery accessible to people in these resource-limited regions. 


\section{Conclusions}

Stereotactic devices per patient population ratios and GKRS device cost relative to GDP vary tremendously. These factors likely affect patient access to stereotactic radiosurgery.

Collaboration of regional medical groups, institutions providing radiosurgical care, and both government and non-governmental organizations could help reduce these limitations to care and improve access to SRS, particularly in resource constrained countries.

Categories: Radiation Oncology, Neurosurgery, Oncology

Keywords: stereotactic radiosurgery, neurosurgery, gross domestic product, disparities, problems, solutions, resource limited countries

\section{Introduction}

Debates concerning the accessibility of new medical technologies to all regions of the world are becoming increasingly prevalent in today's modern era. Stereotactic radiosurgery (SRS), a minimally invasive approach that enables the treatment of selected pathologies with a high degree of precision and accuracy, serves as an interesting example of this issue. Despite the tremendous work achieved by major professional societies (MPS) [e.g. the Radiosurgery Society (RSS), The International Stereotactic Radiosurgery Society (ISRS), the American Association of Neurological Surgeons (AANS), the Congress of Neurological Surgeons (CNS), and the World Federation of Neurosurgical Societies (WFNS)] during the past three decades, SRS devices are only available to a limited number of people in the world [1-6]. Inadequate numbers of trained physicians in SRS, a scarcity of appropriate medical stereotactic devices relative to patient populations, high costs of SRS devices and disparities in education are among the many constraints precluding the establishment of SRS in resource limited countries (RLC). Better strategies need to be developed, especially in RLC, to ensure adequate access and delivery of radiosurgery worldwide.

The purpose of this study is to highlight some of the difficulties concerning access to SRS and suggest possible solutions to this problem. Furthermore, it could help to drive collaboration among doctors, health economists, governmental agencies, and the medical technology industry to work for better accessibility of SRS to the vast majority of the world population. The discrepancy in the implementation of radiosurgery in developed countries and RLC is due to factors that are discussed according to the experiences of the authors in the field of neurosurgery in Africa, Europe, Asia, America, and Latin America.

\section{Materials And Methods}

In this study, we only focus on one SRS device (Gamma Knife). Information on GKRS devices was readily available. Estimated capita per Gamma Knife center ratios for various regions of the world were calculated using Gamma Knife sales information from Elekta (Elekta AB, Stockholm, Sweden), by both direct contact and through their website [7]. Population information from 2012 was obtained from The World Bank website [8]. According to evidence-based data of medical oncology in the United States of America (USA), we estimated that approximately 18\% of nations' gross domestic product (GDP) [8] goes to healthcare spending, approximately $5 \%$ of health care spending goes to cancer care, and approximately $30 \%$ of cancer care could be spent on radiosurgery [9]. To calculate the ability of different countries to pay for Gamma Knife devices, we estimated the cost of one Gamma Knife unit to be 4 million U.S. dollars.

\section{Results}

Marked differences exist worldwide in nations' Gamma Knife centers per capita. Well- 


\section{Cureus}

developed countries, such as the U.S., Canada, Japan, and Korea, possess approximately one Gamma Knife unit per three million people. On the other hand, resource-limited nations in Asia (excluding Japan, Korea, and China) and Africa have only one Gamma Knife unit per 132 million to 370 million people, respectively. Europe, Australia, Central and Latin America, and China possess one Gamma Knife center per 15 million, 36 million, 41 million, and 90 million people, respectively.

\section{Region}

USA/Canada

Japan/Korea

Europe

Australia

Central and

Latin America

China

Asia (except Japan,

Korea, China)

Africa

\section{Per-capita radiosurgery devices}

in million people/GK unit

3

15

36

41

90

132

370

TABLE 1: Estimate of radiosurgery market penetration per-capita in million people/GK unit (Gamma Knife units) ratios for various regions of the world. Figures calculated from data collected from Elekta.

Further disparity exists in the capacity of different regions of the world to pay for the costs of GKRS, as based on their GDP. The European Union and U.S. could theoretically afford the costs of 10x more Gamma Knife units than sub-Saharan Africa (11,225 and 9,400 Gamma Knife units, respectively, compared to 870), and East Asia and Pacific nations could afford the costs of 8x more Gamma Knife units than sub-Saharan Africa (7,054 Gamma Knife units compared to 870). Latin America, Caribbean nations, North Africa, and the Middle East may afford 3,600 and 1,039 Gamma Knife units, respectively. 


\section{Cureus}

\section{Regions}

European Union

U.S.A.

East Asia \& Pacific

Latin America

and Caribbean

Middle East \&

North Africa

Sub-Saharan Africa
Estimated number

of potential GK units

11,225

9,400

7,054

3,600

1,039

870

TABLE 2: Possible number of Gamma Knife units afforded by various regions of the world based on gross domestic product. Note that one Gamma Knife unit was estimated to cost 4 million U.S. dollars.

\section{Discussion}

\section{Accessibility to SRS in RLC}

It is likely that many people living in RLC with radiosurgical pathologies go undiagnosed and untreated as a result of the convergence of various social, political, and cultural circumstances that limit access to care. This point is well-illustrated by the scarcity of Gamma Knife Centers (GKCs) in these areas (Table 1), with the most striking example being Africa, where we estimate approximately 100-fold more capita per GKCs than the U.S., Canada, Japan, and Korea. Economics likely play a major role in this disparity due to the high costs of Gamma Knife technology. Our estimates show that places like the U.S. and Europe have a budget that is at least 10x greater than that of Africa and the Middle East for SRS costs.

Certainly, limited numbers of neurosurgeons in RLC further inhibit accessibility to SRS in these areas. A recent survey by the World Health Organization showed there to be only 79 neurosurgeons in all of sub-Saharan Africa, yielding one neurosurgeon per 3.6 million people [10]. This survey also found that 11 African nations have no practicing neurosurgeons, and in the nations of Uganda and Tanzania, the ratio of trained neurosurgeons to the rest of the population is approximately 1:12,000,000. Due to scarce neurosurgery training centers in these areas, physicians from RLC often go to developed countries for their training. However, many do not return to their home nations due to the lack of medical supplies, technology, staff, and fellow practitioners there, further exacerbating the problem.

Consequently, the lack of medical expertise in many of these areas leads to a poor understanding of neurologic disease at both social and political levels. There are some areas of sub-Saharan Africa, for example, that link brain disease to superstition and magic, preferring witchcraft or a shaman to the expertise of a neurosurgeon [11]. Further, the lack of epidemiological data for central nervous system pathologies in these regions discourages investment in SRS technology. For example, it has been reported that there are 18 countries in 
Africa without a computer tomography (CT) scanner; furthermore, in several countries that do possess a single CT scanner, it is only available to a small subset of people living there [10]. It is very likely then that the prevalence of diseases, such as brain tumor metastases, which are common targets of SRS in developed countries, is heavily underestimated in such areas. This poor epidemiological data provides little incentive for financial support from the public health sector, which funds most large medical projects in RLC. Thus, the culmination of this complex scenario results in a paucity of neurosurgeons in these regions, many of whom do not have the training, funding, tools, social support, or political influence to practice radiosurgery with satisfactory outcomes.

\section{Health care programs in RLC}

The current suboptimal state of healthcare in RLC can be partially attributed to the introduction of modern medicine without the financial means to maintain it. Most developing countries have evolved a fee-for-service model where cash is the main currency for healthcare spending. This system represents the primary method of medical financing in $84.2 \%$ of people in these areas, compared to only $3.6 \%$ of people in high income countries [12]. Since many patients pay out-of-pocket, this limits the market for the introduction of innovative medical technologies, such as SRS. Unfortunately, many people in RLC must pay for substandard therapy with questionable outcomes. Current aid organizations work to send old medical equipment from developed countries to these regions; however, since many of the tools and machines are outdated and without proper maintenance, the positive effects of these outdated devices on the local health care are short-lived.

An additional point of concern exists at the international level, where appropriate evaluative systems for international partnership with governments of RLC are not standard. Despite the fact that many RLC have failed to establish a basic functioning medical system, many international programs have attempted to include them as primary partners in complex health care ventures. It is very unlikely that regions with fragmented medical systems will be able to keep up with such complicated projects.

\section{Solutions to improve SRS accessibility in RLC}

Perhaps the most important place to start to improve the accessibility to SRS in RLC is to increase the awareness in these areas of its expanding role in treating CNS disease. While radiosurgery was initially developed for the treatment of movement disorders and pain [13-14], it is now commonly applied to the treatment of brain tumors [15-22], spinal tumors [23-30], and arteriovenous malformations [31] as well. It will be of tremendous value to educate and inform local politicians and social organizations of the basic tenets of medical neuroscience, which will help to promote the institution of programs to recruit physicians and facilities equipped to treat patients with SRS. Certain areas will likely need a more gradual integration of medical knowledge into their current belief systems, for which region specific interventions could be promoted in accordance with some of the local cultural medical practices. For example, collaboration with traditional healers in some parts of sub-Saharan Africa could be utilized.

International partnership, especially between the MPS, interested academic institutions, and local governments of RLC, will also be vital for the advancement of SRS to unreached regions of the world. Collaborative efforts among these groups could result in the creation of physician reintegration programs for areas of need. Region-specific reintegration programs could take into consideration the local challenges of each area and define guidelines to make the practice of SRS financially and technically more attractive in these regions. By doing so, they may motivate neurosurgeons currently working abroad to return back to their country of origin. Such a system, with local functioning SRS programs and trained local professionals, could reduce the overall cost of medical care in these already impoverished populations by 
reducing expensive patient transfers to outside facilities. Indeed, a more promising, long-term approach is the training of physicians directly in SRS training courses in RLC. However, currently, these areas often lack the social, political, and financial support to establish such programs.

In order to sustain the implementation of SRS technology in these areas, it will be necessary to implement a medical financing system that will enable the local population to afford these medical costs, considering that even in more socially and financially advanced countries, high medical costs present a significant problem. Tax-based funding and social insurance are primary methods of financing in $50 \%$ and $42.8 \%$ of high-income countries, respectively, but these approaches are used in only $10.5 \%$ and $5.3 \%$ of low-income countries, respectively [12]. A potential solution in these countries could be the implementation of a system of tax-based funding and social insurance similar to those of advanced countries. Additionally, an attitude stressing the importance of preventative medicine must be proposed to citizens in RLC. The culture of paying in advance for health should be introduced and promoted as a mandatory part of a financial radiosurgical developmental aid policy to maintain a functional healthcare model that sustains medical practice, as well as the expense of medical technology in the field of SRS.

It is radiosurgical culture to celebrate excellence in technique through meticulous evaluation of outcomes. We believe that when implementing SRS in RLC, it could be necessary to scrutinize the governments and organizations based on what they have accomplished in the past. When considering countries for SRS, only governments with a track record in succeeding with other projects should be considered. Governments that are currently unable to fulfill even the basic governmental tasks that they set out to accomplish will likely fail the challenging task of establishing a radiosurgical system. However, not having a reliable government should not stop the MPS from bringing SRS to these countries. The MPS could collaborate with reliable non-governmental organizations (NGOs), which will enable a more stable continuity of projects independent of the fluctuations linked with governmental and political issues. We recommend that any SRS project initiated or supported by MPS be scrutinized for relative improvements in the level of care delivered to patients in developed countries.

\section{Study limitations}

The study utilizes SRS device data utilized from Elekta. While the Gamma Knife has been a radiosurgical platform produced by the same company for more than 30 years, it is not the only radiosurgical device. Other radiosurgical devices, such as CyberKnife (Accuray), TrueBeam (Varian), Edge (Varian), Tomotherapy (Accuray), Brainlab, Synergy (Elekta), and Trilogy (Varian) are in widespread use throughout the world. The current study does not account for the additional radiosurgical devices nor does it factor in the variability in device purchase or operating cost. Thus, the disparity in radiosurgical access may be an overestimate in some areas where radiosurgery is disproportionately performed by devices other than the Gamma Knife. Also, the amount of health care spending as a proportion of GDP is an estimate and actual spending can be affected by a myriad of factors (e.g. political strife, recession, etc.).

\section{Conclusions}

Marked disparities exist in the accessibility of SRS among developed countries and RLC. These disparities are likely the result of a combination of economic, cultural, social, and political factors that limit the prevalence of both SRS devices and physicians capable of using them in these areas. These factors likely affect patient access to stereotactic radiosurgery. Collaboration of regional medical groups, institutions providing radiosurgical care, and both government and non-governmental organizations could help reduce these limitations to care and improve access to SRS, particularly in resource-constrained countries. 


\section{Additional Information \\ Disclosures}

Human subjects: All authors have confirmed that this study did not involve human participants or tissue. Animal subjects: All authors have confirmed that this study did not involve animal subjects or tissue. Conflicts of interest: In compliance with the ICMJE uniform disclosure form, all authors declare the following: Payment/services info: All authors have declared that no financial support was received from any organization for the submitted work. Financial relationships: David Schlesinger declare(s) a grant from Elekta. The research grant was used for other studies not directly related to this article. Other relationships: All authors have declared that there are no other relationships or activities that could appear to have influenced the submitted work.

\section{References}

1. Abdel-Wahab M, Bourque JM, Pynda Y, Izewska J, Van der Merwe D, Zubizarreta E, Rosenblatt E: Status of radiotherapy resources in Africa: An International Atomic Energy Agency analysis. Lancet Oncol. 2013, 14:e168-75.

http://www.thelancet.com/journals/lanonc/article/PIIS1470-2045(12)70532-6/fulltext.

2. Levin CV, El Gueddari B, Meghzifene A: Radiation therapy in Africa: Distribution and equipment. Radiother Oncol. 1999, 52:79-84.

3. Barton MB, Frommer M, Shafiq J: Role of radiotherapy in cancer control in low-income and middle-income countries. Lancet Oncol. 2006, 7:584-95.

4. Warf BC: Educate one to save a few. Educate a few to save many . World Neurosurg. 2013, 79:S15-8. 10.1016/j.wneu.2010.09.021

5. Haglund MM, Kiryabwire J, Parker S, Zomorodi A, MacLeod D, Schroeder R, Muhumuza M, Merson M: Surgical capacity building in Uganda through twinning, technology, and training camps. World J Surg. 2011, 35:1175-82. 10.1007/s00268-011-1080-0

6. Farmer PE, Kim JY: Surgery and global health: A view from beyond the OR . World J Surg. 2008, 32:533-6. 10.1007/s00268-008-9525-9

7. Elekta Treatment Centers. (2013). Accessed: November 1, 2013:

http://www.elekta.com/patients/treatment-information/treatment-centers.html.

8. TheWorldBank - Data. (2013). Accessed: November 1, 2013: http://data.worldbank.org/indicator/SP.POP.TOTL.

9. Farina K: The Economics of Cancer Care in the United States . American Journal of Managed Care. 2012, http://www.ajmc.com/publications/evidence-based-oncology/2012/2012-2-vol18n1/the-economics-of-cancer-care-in-the-uni....

10. El Khamlichi A: African neurosurgery: Current situation, priorities, and needs. Neurosurg. 2001, 48:1344-7.

11. Awaritefe A: Epilepsy: The myth of a contagious disease . Cult Med Psychiatry. 1989, 13:44956.

12. World Health Organization: Atlas: Country Resources for Neurological Disorders, pg. 32-33, 38-39.. (2004). http://apps.who.int/iris/bitstream/10665/43075/1/9241562838.pdf?ua=1.

13. Leksell L, Meyerson BA, Forster DM: Radiosurgical thalamotomy for intractable pain. Confin Neurol. 1972, 34:264.

14. Svennilson E, Torvik A, Lowe R, Leksell L: Treatment of parkinsonism by stereotactic thermolesions in the pallidal region. A clinical evaluation of 81 cases. Acta Psychiatr Scand. 1960, 35:358-77.

15. Sheehan J, Niranjan A, Flickinger JC, Kondziolka D, Lunsford LD: The expanding role of neurosurgeons in the management of brain metastases. Surg Neurol. 2004, 62:32-41.

16. Siddiqui F, Patel M, Khan M, McLean S, Dragovic J, Jin JY, Movsas B, Ryu S: Stereotactic body radiation therapy for primary, recurrent, and metastatic tumors in the head-and-neck region. Int J Radiat Oncol Biol Phys. 2009, 74:1047-53. 10.1016/j.ijrobp.2008.09.022

17. Siddiqui F, Patel M, Khan M, McLean S, Dragovic J, Jin JY, Movsas B, Ryu S: Stereotactic body radiation therapy for primary, recurrent, and metastatic tumors in the head-and-neck region. Int J Radiat Oncol Biol Phys. 2009, 74:1047-53. 10.1016/j.ijrobp.2008.09.022 
18. Song DY, Kavanagh BD, Benedict SH, Schefter T: Stereotactic body radiation therapy. Rationale, techniques, applications, and optimization. Oncology (Williston Park). 2004, 18:1419-30; discussion 1430, 1432, 1435-6.

19. Song DY, Williams JA: Fractionated stereotactic radiosurgery for treatment of acoustic neuromas. Stereotact Funct Neurosurg. 1999, 73:45-9.

20. Varlotto JM, Shrieve DC, Alexander E, 3rd, Kooy HM, Black PM, Loeffler JS: Fractionated stereotactic radiotherapy for the treatment of acoustic neuromas: Preliminary results. Int J Radiat Oncol Biol Phys. 1996, 36:141-5.

21. Combs SE, Widmer V, Thilmann C, Hof H, Debus J, Schulz-Ertner D: Stereotactic radiosurgery (SRS): Treatment option for recurrent glioblastoma multiforme (GBM). Cancer. 2005, 104:2168-73.

22. Cho KH, Hall WA, Gerbi BJ, Higgins PD, McGuire WA, Clark HB: Single dose versus fractionated stereotactic radiotherapy for recurrent high-grade gliomas. Int J Radiat Oncol Biol Phys. 1999, 45:1133-41.

23. Do L, Pezner R, Radany E, Liu A, Staud C, Badie B : Resection followed by stereotactic radiosurgery to resection cavity for intracranial metastases. Int J Radiat Oncol Biol Phys. 2009, 73:486-91.

24. Benzil DL, Saboori M, Mogilner AY, Rocchio R, Moorthy CR: Safety and efficacy of stereotactic radiosurgery for tumors of the spine. J Neurosurg. 2004, 101:413-8.

25. Bilsky MH, Yamada Y, Yenice KM, Lovelock M, Hunt M, Gutin PH, Leibel SA: Intensitymodulated stereotactic radiotherapy of paraspinal tumors: A preliminary report. Neurosurg. 2004, 54:823-31.

26. Chang EL, Shiu AS, Lii MF, Rhines LD, Mendel E, Mahajan A, Weinberg JS, Mathews LA, Brown BW, Maor MH, Cox JD: : Phase I clinical evaluation of near-simultaneous computed tomographic image-guided stereotactic body radiotherapy for spinal metastases. Int J Radiat Oncol Biol Phys. 2004, 59:1288-94.

27. De Salles AA, Pedroso AG, Medin P, Agazaryan N, Solberg T, Cabatan-Awang C, Espinosa DM, Ford J, Selch MT: Spinal lesions treated with Novalis shaped beam intensity-modulated radiosurgery and stereotactic radiotherapy. J Neurosurg. 2004, 101:435-40.

28. Finn MA, Vrionis FD, Schmidt MH: Spinal radiosurgery for metastatic disease of the spine . Cancer Control. 2007, 14:405-11.

29. Milker-Zabel S, Zabel A, Thilmann C, Schlegel W, Wannenmacher M, Debus J: Clinical results of retreatment of vertebral bone metastases by stereotactic conformal radiotherapy and intensity-modulated radiotherapy. Int J Radiat Oncol Biol Phys. 2003, 55:162-7.

30. Rock JP, Ryu S, Yin FF: Novalis radiosurgery for metastatic spine tumors . Neurosurg Clin N Am. 2004, 15:503-9.

31. Ryu S, Jin R, Jin JY, Chen Q, Rock J, Anderson J, Movsas B: Pain control by image-guided radiosurgery for solitary spinal metastasis. J Pain Symptom Manage. 2008, 35:292-8.

32. Lee SH, Lim YJ, Choi SK, Kim TS, Rhee BA: Radiosurgical considerations in the treatment of large cerebral arteriovenous malformations. J Korean Neurosurg Soc. 2009, 46:378-84. 